\title{
Regulation of an Aplysia Bag Cell Neuron Cation Channel by Closely Associated Protein Kinase A and a Protein Phosphatase
}

\author{
Neil S. Magoski \\ Department of Physiology, Queen's University, Kingston, Ontario K7L 3N6, Canada
}

Ion channel regulation by closely associated kinases or phosphatases has emerged as a key mechanism for orchestrating neuromodulation. An exemplary case is the nonselective cation channel that drives the afterdischarge in Aplysia bag cell neurons. Initial studies showed that this channel is modulated by both a closely associated PKC and a serine/threonine protein phosphatase (PP). In excised, inside-out patches, the addition of ATP (a phosphate source) increases open probability $\left(\mathrm{P}_{0}\right)$ through PKC, and this is reversed by the PP. Previous work also reported that, in certain cases, ATP can decrease cation channel $P_{0}$. The present study characterizes and provides a mechanism for this decreased $P_{0}$ ATP response. The kinetic change for channels inhibited by ATP was identical to the previously reported effect of exogenously applied protein kinase $\mathrm{A}$ (PKA) (i.e., a lengthening of the third closed-state time constant). The decreased $\mathrm{P}_{0}$ ATP response was blocked by the PKA inhibitor peptide $\mathrm{PKA}_{6-22}$, and its reversal was prevented by the PP inhibitor microcystin-LR. Furthermore, $\mathrm{PKA}_{6-22}$ did not alter the increased $\mathrm{P}_{\mathrm{O}}$ ATP response. This suggests that both PKA and a PP are closely associated with these cation channels, but PKA and PKC are not simultaneously targeted. After an afterdischarge, the bag cell neurons are refractory and fail to respond to subsequent stimulation. The association of PKA with the cation channel may contribute to this decrease in excitability. Altering the constituents of a regulatory complex, such as exchanging PKA for PKC, may represent a general mechanism to precisely control ion channel function and excitability.

Key words: Aplysia; bag cell neurons; cation channel; phosphorylation; protein kinase A; excitability

\section{Introduction}

One of the primary means for initiating changes to neuronal excitability is phosphorylation-dependent ion channel regulation (Hille, 2001; Levitan and Kaczmarek, 2002; Magoski and Kaczmarek, 2003). Increasingly, the kinases and phosphatases that mediate this regulation are found closely associated with particular ion channels (Chung et al., 1991; Bielefeldt and Jackson, 1994; Rosenmund et al., 1994; Reinhart and Levitan, 1995; Holmes et al., 1996; Yu et al., 1997; Tibbs et al., 1998; Brandon et al., 1999; Tsunoda and Zucker, 1999; Davare et al., 2001; Huang et al., 2001; Marx et al., 2002; Nitabach et al., 2002; Zhou et al., 2002; Gingrich et al., 2004). The present study describes the regulation of a cation channel from Aplysia bag cell neurons by kinase and phosphatase activities closely associated with the channel in excised, inside-out patches.

The bag cell neurons initiate egg-laying behavior in Aplysia californica through a marked change in excitability called the af-

Received May 4, 2004; revised June 10, 2004; accepted June 14, 2004.

This work was supported by a Canadian Institutes of Health operating grant, a Canada Foundation for Innovation new opportunities grant, an Ontario Innovation Trust new opportunities grant, and a Queen's University research initiation grant to N.S.M. I am very grateful to S. L. Smith for excellent technical assistance and N.M. Magoski for critical evaluation of previous drafts of this manuscript.

Correspondence should be addressed to Dr. N. S. Magoski, Department of Physiology, Queen's University, Fourth Floor, Botterell Hall, 18 Stuart Street, Kingston, Ontario K7L 3N6, Canada. E-mail: magoski@post.queensu.ca. DOI:10.1523/JNEUROSCI.1694-04.2004

Copyright $\odot 2004$ Society for Neuroscience $\quad$ 0270-6474/04/246833-09\$15.00/0 terdischarge (Kupfermann, 1967; Kupfermann and Kandel, 1970; Pinsker and Dudek, 1977; Rothmann et al., 1983; Conn and Kaczmarek, 1989). This $\sim 30$ min barrage of action potentials is triggered by synaptic input and results in the neurohemal secretion of egg-laying hormone. On termination of the afterdischarge, the bag cell neurons become refractory for $\sim 18 \mathrm{hr}$, during which time additional afterdischarges cannot be induced. The inward current that drives the afterdischarge is provided by a nonselective cation channel (Wilson and Kaczmarek, 1993; Wilson et al., 1996). Previous work demonstrated that this channel was activated by a closely associated PKC, the effects of which could be reversed by a similarly targeted protein phosphatase (PP) (Wilson et al., 1998; Magoski et al., 2002). Both PKC and the PP were found to be constitutively active in excised, inside-out patches, and phosphorylation could be achieved by simply adding a phosphate source, such as ATP, to the cytoplasmic face of the channel.

However, more recent studies have shown that, in certain cases, rather than upregulating the cation channel, the application of ATP could, in fact, decrease activity (Magoski 2003; N. S. Magoski and L. K. Kaczmarek, unpublished observations). Interestingly, Wilson and Kaczmarek (1993) demonstrated that when exogenous protein kinase A (PKA) was applied to the cytoplasmic face of the channel, activity was decreased. Building on this, the present study shows that the ATP-induced decrease of cation channel activity is attributable to a closely associated PKA using 
ATP as a phosphate source to phosphorylate the channel or a nearby protein. Furthermore, the data will show that this phosphorylation is reversed by a similarly closely associated PP. Wilson and Kaczmarek (1993) proposed that PKA may be responsible for lowering channel activity at the end of the afterdischarge, to discourage bursting during the refractory period. As such, the channel-PKA association documented here would facilitate refractoriness. In general, by exchanging the enzymes targeted to an ion channel (e.g., switching PKA for PKC), it would be possible to regulate ion channel function and excitability in an exact and reliable manner over the long term.

\section{Materials and Methods}

Animals and cell culture. Adult Aplysia californica weighing 150-300 gm were obtained from Marine Specimens Unlimited (San Francisco, CA) or Marinus Inc. (Long Beach, CA). Animals were housed in an $\sim 4001$ aquarium containing continuously circulating, aerated sea water (Kent sea salt; Kent Marine, Acworth, GA) at $14-16^{\circ} \mathrm{C}$ on a $12 \mathrm{hr}$ light/dark cycle and fed romaine lettuce three to five times per week.

For primary cultures of isolated bag cell neurons, animals were anesthetized with an injection of isotonic $\mathrm{MgCl}_{2}$ ( $\sim 50 \%$ of body weight), and the abdominal ganglion was removed and treated with neutral protease (13.33 mg/ml; catalog \#165859; Roche Diagnositics, Indianapolis, IN) for $18 \mathrm{hr}$ at $18-20^{\circ} \mathrm{C}$, dissolved in normal artificial sea water (nASW; 460 mм NaCl, $10.4 \mathrm{~mm} \mathrm{KCl}, 11 \mathrm{~mm} \mathrm{CaCl}$, $55 \mathrm{~mm} \mathrm{MgCl}_{2}$, 15 mм HEPES, 1 $\mathrm{mg} / \mathrm{ml}$ glucose, $100 \mathrm{U} / \mathrm{ml}$ penicillin, and $0.1 \mathrm{mg} / \mathrm{ml}$ streptomycin, $\mathrm{pH} 7.8$ with $\mathrm{NaOH}$ ). The ganglion was then transferred to fresh nASW, and the bag cell neuron clusters were dissected from their surrounding connective tissue. Using a fire-polished Pasture pipette and gentle titration, neurons were dispersed in nASW onto $35 \times 10 \mathrm{~mm}$ polystyrene tissue culture dishes (catalog \#430165; Corning, Corning, NY). Cultures were maintained in nASW for $1-3 \mathrm{~d}$ in a $14^{\circ} \mathrm{C}$ incubator, and experiments were performed on neurons that were in vitro for at least $1 \mathrm{~d}$. Salts were obtained from Fisher (Ottawa, Ontario, Canada), ICN (Aurora, OH), or Sigma-Aldrich (St. Louis, MO).

Excised, inside-out patch-clamp recording. A single cation channel current was measured using an EPC-8 amplifier (HEKA Electronics, Mahone Bay, Nova Scotia, Canada) and the excised, inside-out patch-clamp method. Microelectrodes were pulled from borosilicate glass capillaries ( $1.5 \mathrm{~mm}$ internal diameter; model TW 150 F-4; World Precision Instruments, Sarasota, FL) and were fire polished to a resistance of $2-5 \mathrm{M} \Omega$ when filled with nASW (composition as above but lacking glucose, penicillin, and streptomycin). After excision, the cytoplasmic face was bathed with artificial intracellular saline (in mм: $500 \mathrm{~K}$-aspartate, $70 \mathrm{KCl}$, $0.77 \mathrm{CaCl}_{2}, 1.2 \mathrm{MgCl}_{2}, 10 \mathrm{HEPES}, 11$ glucose, 5 EGTA, and 10 reduced glutathione, $\mathrm{pH} 7.3$ with $\mathrm{KOH}$; free $\left[\mathrm{Ca}^{2+}\right]=1 \mu \mathrm{M}$, calculated using the CaBuffer program, courtesy of Dr. L. Schlichter, University of Toronto, Toronto, Canada). Salts were from Fisher, ICN, or Sigma-Aldrich. Current was low-pass filtered at $1 \mathrm{kHz}$ using the EPC8 Bessel filter and acquired at a sampling rate of $10 \mathrm{kHz}$ using an IBM-compatible personal computer, a Digidata 1300 analog-to-digital converter (Axon Instruments, Union City, CA), and the Clampex acquisition program of pCLAMP (version 8; Axon Instruments). Data were gathered at room temperature $\left(18-20^{\circ} \mathrm{C}\right)$ in $1-3$ min intervals while holding the patch at $-60 \mathrm{mV}$ or, to avoid occasional contamination by $\mathrm{Ca}^{2+}$-activated $\mathrm{K}^{+}$ currents, $-80 \mathrm{mV}$. All experiments were performed on the more commonly encountered continuously active cation channels as opposed to the rarely encountered burster channels (Wilson and Kaczmarek, 1993). Continuously active channels always show some level of activity when monitored for a minute or longer, whereas burster channels have additional, extremely long closures that last for several minutes. Thus, it is a straightforward matter to distinguish continuously active channels from burster channels, given that, even if the open probability $\left(\mathrm{P}_{\mathrm{O}}\right)$ of a continuously active channel is low to begin with, there will always be periodic openings.

Reagents and drug application. Most drugs were introduced into the bath by pipetting a small volume $(<10 \mu \mathrm{l})$ of concentrated stock solution into the culture dish ( $2 \mathrm{ml}$ volume). Care was taken to pipette the stock near the side of the dish and as far away as possible from the patch at the tip of the microelectrode. ATP was obtained from either Sigma-Aldrich (grade $2,2 \mathrm{Na}^{+}$salt; catalog \#A3377) or from ICN $\left(2 \mathrm{Na}^{+}\right.$salt; catalog $\# 194613), \mathrm{PKA}_{6-22}$ (P6062) and okadaic acid $\left(\mathrm{K}^{+}\right.$salt; catalog \#O7885) were both obtained from Sigma-Aldrich, and microcystin-LR (catalog \#475815) was obtained from Calbiochem (San Diego, CA).

Analysis. To determine single-channel $\mathrm{P}_{\mathrm{O}}$ and make statistical descriptions of channel kinetics, events lists were made from single-channel data files using the half-amplitude threshold criterion (Colquhoun and Sigworth, 1995) of the Fetchan analysis program of pClamp. Fetchan was also used to generate all-points histograms for determining channel amplitude. For analysis, most data did not require additional filtering below the $1 \mathrm{kHz}$ used during acquisition; however, to avoid inclusion of noiserelated "events" as channel openings, some data were filtered a second time using the Fetchan digital Gaussian filter to a final cutoff frequency of $500 \mathrm{~Hz}$. For display in the figures, some data were filtered to a final cutoff frequency of $500 \mathrm{~Hz}$ or $250 \mathrm{~Hz}$.

The Pstat analysis program of pClamp was used to read events lists and determine $\mathrm{P}_{\mathrm{O}}$, either automatically or manually, using the formula: $P_{\mathrm{O}}=$ $\left(t_{1}+t_{2}+\ldots t_{\mathrm{n}}\right) / N \times t_{\text {tot }}$, where $t$ is the amount of time that $n$ channels are open, $N$ is the number of channels in the patch, and $t_{\text {tot }}$ is the time interval over which $\mathrm{P}_{\mathrm{O}}$ is measured. The number of channels in the patch was determined by counting the number of unitary current levels, particularly at more positive voltages (typically $-20 \mathrm{mV}$ ). Pstat was also used to generate single-channel open and closed dwell-time histograms and fit them with an exponential function describing the kinetic behavior of the channel. The time interval ( $x$-axis) was binned logarithmically at $10 \mathrm{bins} /$ decade, and histograms were fit with an exponential function using the maximum likelihood estimator method and a simplex search (Colquhoun and Sigworth, 1995), which was given the number of exponentials and estimated time constants $(\tau \mathrm{s})$ at the start. Kinetic analysis was performed exclusively on patches that contained only one cation channel, as determined by a consistent display of a single open current level at more positive voltages (typically $-20 \mathrm{mV}$ ). These channels also had to have a high enough initial $\mathrm{P}_{\mathrm{O}}$ such that there were sufficient events to plot dwell-time histograms for reliable fitting. In practice, this translated into a minimum of 500 events for such histograms. Considering the recording periods used here (typically $3 \mathrm{~min}$ ), along with an average open time of $\sim 7 \mathrm{msec}$, the $\mathrm{P}_{\mathrm{O}}$ had to be at least 0.02 to generate 500 events. Indeed, the $\mathrm{P}_{\mathrm{O}}$ of the true single channels used for kinetic analysis was always above 0.02 and averaged $\sim 0.1$. Pstat was used yet again to determine the mean open and closed state current level by fitting all-points histograms with Gaussian functions using the least-squares method and a simplex search. Channel current amplitude was then calculated by subtracting the mean closed current level from the mean open current level at a given voltage.

To make $\mathrm{P}_{\mathrm{O}}$ versus voltage relationships, $\mathrm{P}_{\mathrm{O}}$ was first normalized by dividing by the maximal $\mathrm{P}_{\mathrm{O}}(-20 \mathrm{mV})$, which was then plotted against a patch-holding potential using Origin (version 7; OriginLab, Northampton, MA). This relationship was then fit with a Boltzmann function using Origin to derive the half-maximal voltage $\left(V_{0.5}\right)$ and the slope factor $(k)$. Channel current versus voltage relationships were produced in Origin by plotting channel current amplitude against patch-holding potential, and single-channel conductance $(g)$ was then determined by linear regression.

Data are presented as the mean and SEM. When appropriate, statistical analysis was performed using Instat (version 3; GraphPad Software, San Diego, CA). Student's $t$ test (two-tailed and paired or unpaired) or the Wilcoxon matched-pairs test (two-tailed) was used to test whether the mean differed between two groups. A one-sample $t$ test was used to test whether a mean differed from zero. Data were considered significantly different if the $p$ value was $<0.05$.

\section{Results \\ ATP decreased cation channel activity in excised, inside-out patches}

To record cation channels from cultured bag cell neurons, we used the excised, inside-out patch-clamp technique (Fig. 1A). With nASW bathing the extracellular face and artificial intracel- 


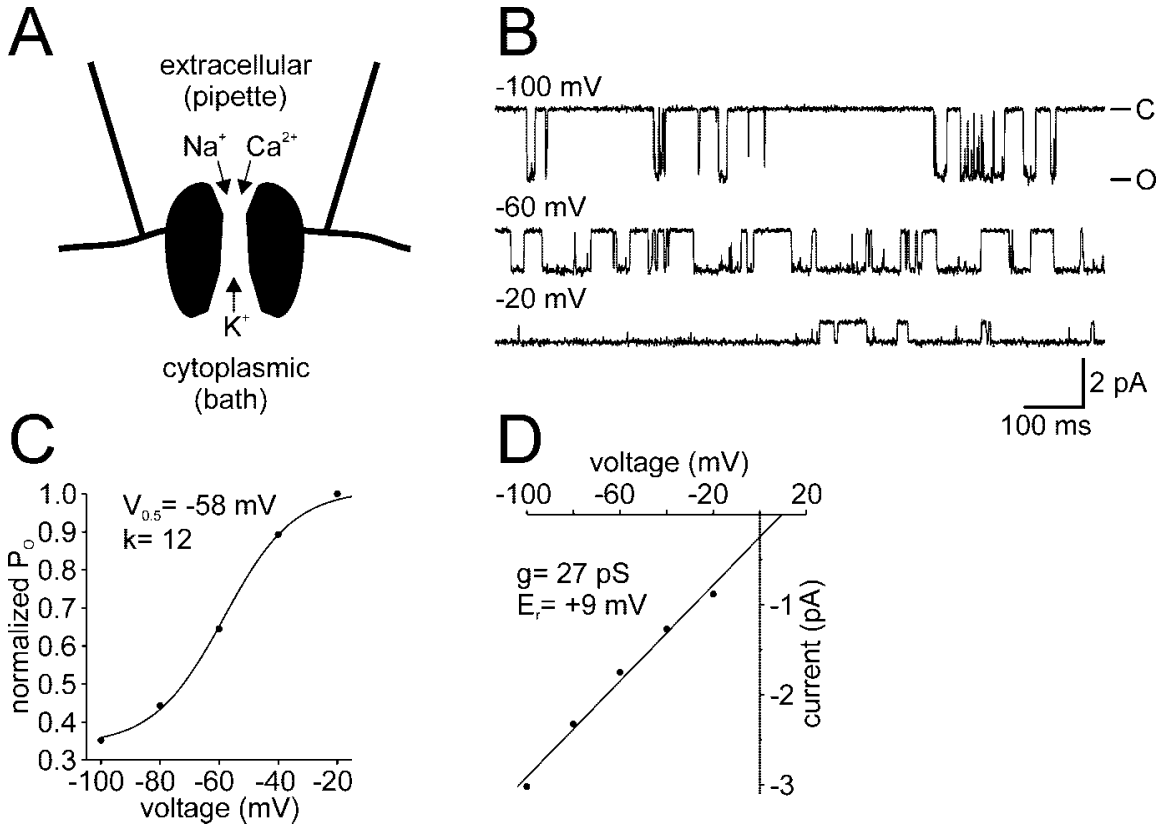

Figure 1. A cation channel in excised, inside-out patches. $A$, Diagrammatic representation of the bag cell neuron cation channel in an excised, inside-out patch (based on Wilson et al., 1996, 1998; Magoski et al., 2002). For the purposes of this study, the recording configuration is such that the extracellular face is within a pipette filled with nASW, whereas the cytoplasmic face is in a bath (tissue culture dish) containing artificial intracellular saline. Under these approximate physiological conditions, the channel is permeable to $\mathrm{Na}^{+}, \mathrm{K}^{+}$, and $\mathrm{Ca}^{2+}$ ions. $B$, Cation channel activity in an excised, inside-out patch at different steadystate holding potentials. Top trace, At $-100 \mathrm{mV}$, the cation channel is seen as brief, unitary, inward current deflections of $\sim 3 \mathrm{pA}$. The closed state is at the top of the trace and designated by $-C$, whereas the open state is at the bottom and designated by -0 . Middle trace, At $-60 \mathrm{mV}$, the channel opens and closes repeatedly. Bottom trace, At $-20 \mathrm{mV}$, the channel is open much of the time. Note that at all holding potentials, the single-channel current shows no voltage-dependent inactivation. $C_{,}$Normalized $P_{0}$ versus voltage curve for the channel shown in $B . P_{0}$ was calculated over the entire time (usually 1-3 min; see Materials and Methods) at the given holding potentials $(-100,-60,-20$ as well as -80 and -40$)$. $P_{0}$ was normalized by dividing by the $P_{0}$ at $-20 \mathrm{mV}$, plotted against voltage, and the points fit with a Boltzmann function. The Boltzmann provides half-maximal voltage $\left(V_{0.5}\right)$ of activation and the slope factor $(k)$ (i.e., the change in voltage required to move the $\left.P_{0} e-f o l d\right)$. $D$, Channel current versus voltage relationship for the channel shown in $B$. Channel current amplitude at a particular voltage was derived from Gaussian fits of all-points histograms (see Materials and Methods). This was plotted against patch-holding potential and fit with linear regression to determine single-channel conductance $(g)$ and, based on the $X$-intercept, the predicted reversal potential $\left(E_{\mathrm{r}}\right)$.
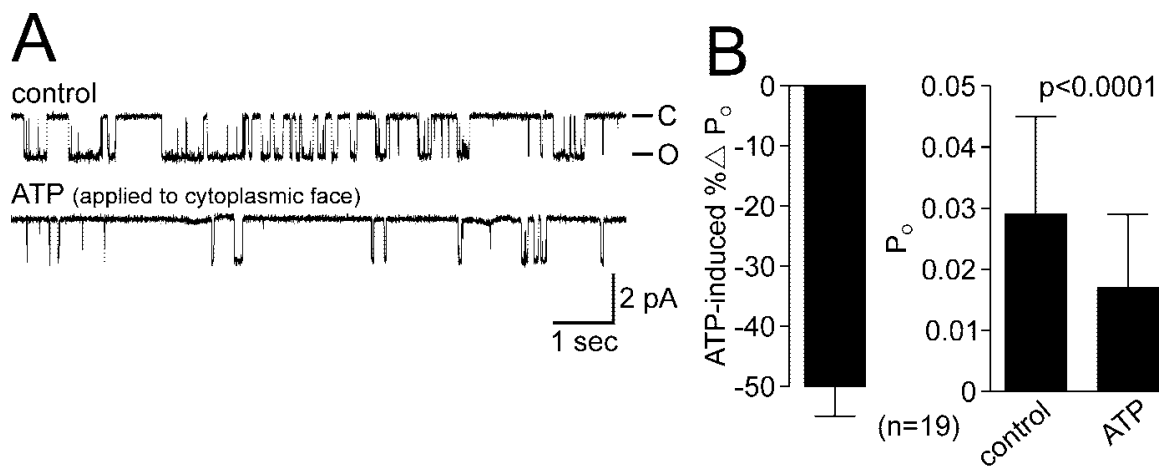

Figure 2. Inhibition of the cation channel by ATP. A, ATP inhibits the cation channel. Top trace, Control recording of a cation channel in an excised, inside-out patch. Bottom trace, Applying $1 \mathrm{~mm}$ ATP to the cytoplasmic face of the patch initiates a maintained drop in $P_{0}$. The patch was held at $-60 \mathrm{mV}$. B, Summary of ATP-induced decrease in $P_{0}$. Left graph, In 19 cation channelcontaining patches used as initial tests or parallel controls, application of $1 \mathrm{~mm} \mathrm{ATP}$ causes an $\sim 50 \%$ decrease in $\mathrm{P}_{0}$. Right graph, ATP produces a statistically significant decrease in $\mathrm{P}_{0}$ from a control mean of -0.029 to a mean in ATP of $-0.017(p<0.001$; Wilcoxon matched-pairs test).

lular saline bathing the cytoplasmic face, currents recorded from cation channels showed characteristics essentially identical to those reported previously (Wilson and Kaczmarek, 1993; Wilson et al., 1996, 1998; Magoski et al., 2002). Specifically, the channels lacked voltage-dependent inactivation, displayed voltage-dependent opening (increased $\mathrm{P}_{\mathrm{O}}$ with depolarization), had a conductance of $25-30 \mathrm{pS}(\sim 2 \mathrm{pA}$ at $-60 \mathrm{mV})$, and showed a predicted reversal potential of approximately +10 $\mathrm{mV}$ (Fig. $1 B-D$ ).

Previous studies demonstrated that the application of ATP to the cytoplasmic face of the cation channel resulted in an increased $\mathrm{P}_{\mathrm{O}}$ (Wilson et al., 1998; Magoski et al., 2002). The enhanced activity was attributable to a closely associated PKC, the effects of which could be reversed by a similarly closely associated PP. Subsequent investigations reported that in $\sim 30 \%$ of cation channel-containing patches excised from the bag cell neurons of many Aplysia, there was an obvious decrease in $\mathrm{P}_{\mathrm{O}}$ after the application of $1 \mathrm{~mm}$ ATP (Magoski, 2003; Magoski and Kaczmarek, unpublished observations). In the experiments described here, the decreased $\mathrm{P}_{\mathrm{O}}$ ATP response was characterized by a rapid and sustained drop in cation channel $\mathrm{P}_{\mathrm{O}}$ that lasted for the remainder of the recording period (up to $15 \mathrm{~min}$ ) (Fig. 2A). This inhibition resulted in an $\sim 50 \%$ decrease in $\mathrm{P}_{\mathrm{O}}$ with a $\mathrm{P}_{\mathrm{O}}$ change from a mean of 0.029 in control to a mean of 0.017 in ATP $(n=19$ patches) (Fig. $2 B$ ). The present study explores the mechanism underlying the decreased $\mathrm{P}_{\mathrm{O}}$ ATP response.

Kinetic analysis of channel behavior can provide insight regarding the biophysical and/or mechanistic basis of a change in phenotype. Accordingly, the closed- and open-state dwell times were examined before and after a decreased $\mathrm{P}_{\mathrm{O}}$ ATP response in true, single-channel patches (for criteria, see Materials and Methods; $n=7$ channels/patches) (Fig. 3A). The kinetic profile of the cation channel in control conditions (Fig. 3B, top graphs) was the same as reported previously (Wilson and Kaczmarek, 1993; Magoski et al., 2002), with the closed dwell-time histogram best fit by a three-exponential component $\left(t_{\mathrm{C} 1}\right.$, $t_{\mathrm{C} 2}$, and $\left.t_{\mathrm{C} 3}\right)$ and the open dwell-time histogram best fit by a two-exponential component $\left(t_{\mathrm{O} 1}\right.$ and $\left.t_{\mathrm{O} 2}\right)$. The decreased $\mathrm{P}_{\mathrm{O}}$ ATP response (Fig. $3 B$, bottom graphs) did not change the number of exponentials required to describe the closed or open times, nor did it lead to significant alterations in $t_{\mathrm{C} 1}, t_{\mathrm{C} 2}, t_{\mathrm{O} 1}$, and $t_{\mathrm{O} 2}$. However, a consistent increase in $t_{\mathrm{C} 3}$ was observed after the introduction of ATP, which is best seen by noting the slight rightward shift and overall increase in the rightmost peak of the closed-time histogram. The summary data for these seven cation channels (Fig. 3 C) showed that ATP induced an $\sim 40 \%$ decrease in $\mathrm{P}_{\mathrm{O}}$ without changing channel amplitude. The decrease in $\mathrm{P}_{\mathrm{O}}$ was the result of a near $40 \%$ increase in $t_{\mathrm{C} 3}$, whereas the remaining closedand open-state time constants were not altered appreciably. 

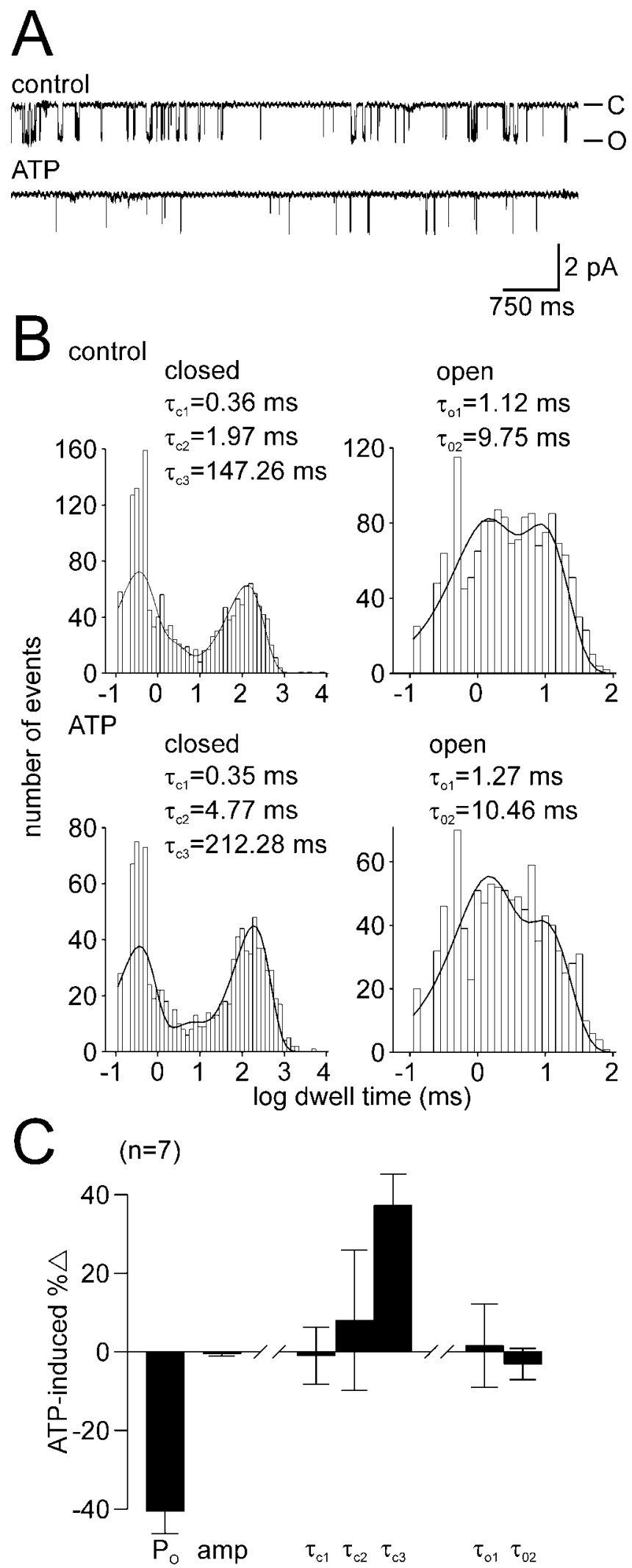

Figure 3. Kinetic analysis of the decreased $P_{0}$ ATP response. $A$, ATP inhibits a single cation channel. Top trace, Control recording of a true, single cation channel in an excised, inside-out patch. Bottom trace, Exposure of the cytoplasmic face of the patch to $1 \mathrm{~mm}$ ATP results in a decrease in $P_{0}$. The patch was held at $-60 \mathrm{mV}$. $B$, Single channel closed and open dwell times are plotted as histograms along with a fit of a sum of exponentials (see Materials and Methods). The time constants for the exponential fits are given in the inset of each graph. During the control period (top graphs), channel closed times are best fit by three exponentials $\left(t_{c 1}, t_{c_{2}}\right.$, and
A PKA inhibitor prevented the decreased $P_{O}$ ATP response Comparison of the kinetic analysis for the decreased $\mathrm{P}_{\mathrm{O}}$ ATP response with previous studies of the cation channel pointed to a possible mechanism for the effect. Specifically, Wilson and Kaczmarek (1993) showed that application of exogenous PKA to the cytoplasmic face of the cation channel decreased $\mathrm{P}_{\mathrm{O}}$ by $\sim 40 \%$, and this was the result of an increase of similar magnitude in the duration of $t_{\mathrm{C} 3}$. The similarity between the effect of exogenous PKA and the decreased $\mathrm{P}_{\mathrm{O}}$ ATP response suggested that the latter was mediated by a PKA-like activity. Furthermore, given that the response was evident in excised, inside-out patches, the kinase must be closely associated with the channel. To test this, $\mathrm{PKA}_{6-22}$, a very specific PKA inhibitor peptide (Glass et al., 1989) that is effective in Aplysia (Adams and Levitan, 1982) as well as the bag cell neurons (Conn et al., 1989), was tested on the decreased $\mathrm{P}_{\mathrm{O}}$ ATP response. Parallel controls of standard decreased $\mathrm{P}_{\mathrm{O}}$ ATP responses were performed on sister cultures (i.e., bag cell neurons isolated from the same animal and maintained in vitro for a similar period of time; $n=6$ patches) (Fig. $4 A$ ). For the inhibitor, patches were excised into artificial intracellular saline containing $1 \mu \mathrm{M} \mathrm{PKA}_{6-22}$, and after a recording period in peptide alone, ATP was applied. $\mathrm{PKA}_{6-22}$ consistently prevented the decreased $\mathrm{P}_{\mathrm{O}}$ ATP response ( $n=7$ patches) (Fig. $4 B$ ). On average, the parallel controls showed an $\sim 50 \%$ decrease in $\mathrm{P}_{\mathrm{O}}$ with ATP, whereas in the presence of $\mathrm{PKA}_{6-22}$, the effect of ATP on $\mathrm{P}_{\mathrm{O}}$ was negligible (Fig. 4C).

A PKA inhibitor also reversed the decreased $P_{O}$ ATP response The previous description of cation channel modulation by a closely associated protein kinase was that of PKC-dependent upregulation; furthermore, the effects of PKC could be reversed by a PP that was also targeted to the channel (Wilson et al., 1998; Magoski et al., 2002). As an initial step in determining whether a $\mathrm{PP}$, capable of reversing the decreased $\mathrm{P}_{\mathrm{O}}$ ATP response, was associated with the cation channel, $\mathrm{PKA}_{6-22}$ was applied after ATP. The anticipated outcome of this would be that inhibition of the kinase would allow any phosphatase activity present in the patch to dephosphorylate the channel and return $\mathrm{P}_{\mathrm{O}}$ to its former level. The decrease in $\mathrm{P}_{\mathrm{O}}$ produced by ATP during these experiments was reversed back to control values with the subsequent introduction of $\mathrm{PKA}_{6-22}(n=5$ patches) (Fig. $5 A)$. The change in $\mathrm{P}_{\mathrm{O}}$ amounted to an $\sim 45 \%$ drop, which was followed by a $\sim 150 \%$ increase with $\mathrm{PKA}_{6-22}$ (Fig. $5 B$ ). It is expected that the percentage change seen after the addition of $\mathrm{PKA}_{6-22}$ would involve a seemingly large increase, because the activity must be elevated from a relatively low value in the presence of ATP compared with control.

\section{PP inhibition prevented reversal of the decreased $P_{O}$ ATP response}

If reversal of the decreased $\mathrm{P}_{\mathrm{O}}$ ATP response by $\mathrm{PKA}_{6-22}$ was attributable to the inhibition of PKA allowing for the activity of a PP to be observed, it follows that previous inhibition of the PP

$\leftarrow$

$\left.t_{C_{3}}\right)$, and the open times by two exponentials $\left(t_{01}\right.$ and $\left.t_{02}\right)$. When ATP is added (bottom graphs), the $t_{\mathrm{C}_{1}}$ or $t_{\mathrm{C} 2}$ change only slightly, whereas $t_{\mathrm{C} 3}$ is obviously larger (an over $40 \%$ increase from $\sim 150$ to $\sim 215 \mathrm{msec}$. For the open times in ATP, neither $t_{01}$ nor $t_{02}$ show any overt change. $C$, Summary data for the decreased $P_{0}$ ATP response of true, single-cation channels. For these seven channels/patches, ATP reduces $P_{0}$ by $\sim 40 \%$ with no change in channel current amplitude (amp). On average, although there is no real change in the first two closed-state time constants $\left(t_{C_{1}}\right.$ and $\left.t_{\mathrm{C} 2}\right)$, the third $\left(t_{\mathrm{C}_{3}}\right)$ shows an $\sim 40 \%$ increase with ATP. For the open-state time constants $\left(t_{01}\right.$ and $\left.t_{02}\right)$, there is no net change with ATP. 


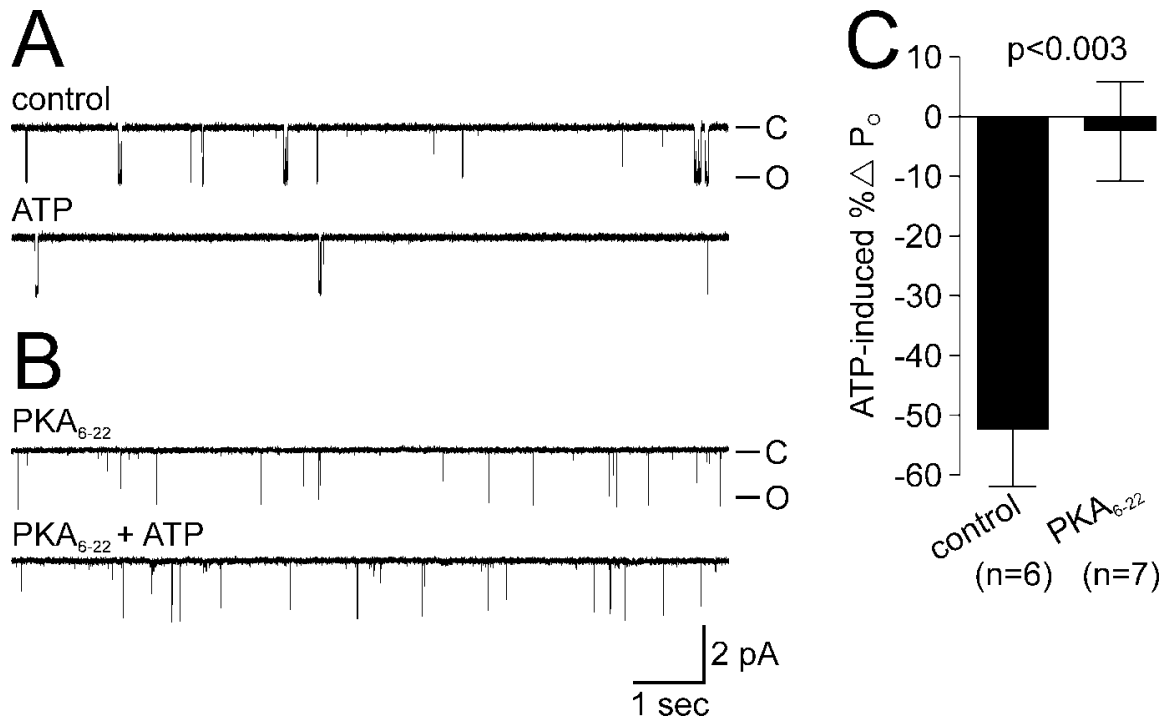

Figure 4. The decreased $P_{0}$ ATP response is blocked by pretreatment with $P K A_{6-22}$. A, A parallel control decreased $P_{0}$ ATP response. Top trace, $A$ control cation channel recorded in an excised, inside-out patch. Bottom trace, Addition of $1 \mathrm{~mm}$ ATP to the cytoplasmic face of the patch produces a decrease in $P_{0}$. The patch was held at $-60 \mathrm{mV}$. $B$, The presence of PKA ${ }_{6-22}$ prevents the decreased $\mathrm{P}_{0}$ ATP response. Top trace, Recording of a cation channel with $1 \mu \mathrm{m} \mathrm{PKA}_{6-22}$ bathing the cytoplasmic face of the patch. Bottom trace, Introduction of $1 \mathrm{~mm}$ ATP along with PKA $_{6-22}$ does not result in a $P_{0}$ change. The patch was held at $-60 \mathrm{mV}$. $C$, Summary data for the effect of ATP on cation channels in the absence or presence PKA $6-22$. Under control conditions, ATP elicits an $\sim 50 \%$ decrease in $\mathrm{P}_{0}$ ( $n=6$ patches), whereas in the presence of $\mathrm{PKA}_{6-22}$, the mean change is just below $0 \%$ ( $n=7$ patches; $p<0.003$; unpaired Student's $t$ test).
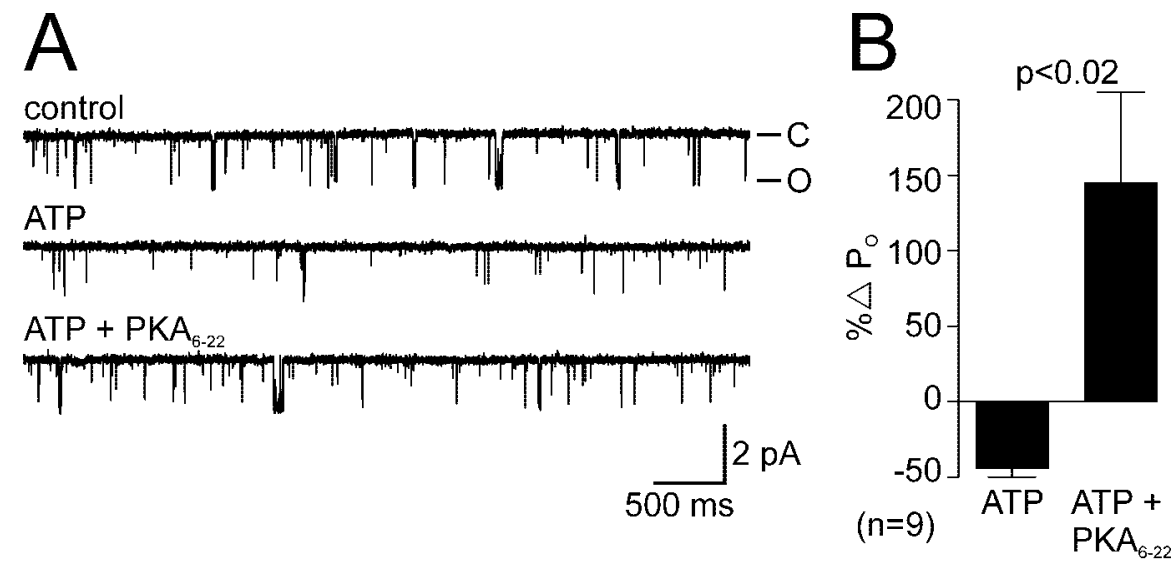

Figure 5. The decreased $P_{0}$ ATP response is reversed by subsequent application of $P K A_{6-22} \cdot A$, Reversal of the decreased $P_{0}$ ATP response by $\mathrm{PKA}_{6-22}$. Top trace, A cation channel recorded in the excised, inside-out configuration. Middle trace, ATP (1 mM) applied to the cytoplasmic face of the patch decreases $P_{0}$. Bottom trace, Addition of $1 \mu \mathrm{M} \mathrm{PKA}_{6-22}$ in the maintained presence of ATP results in restoration of $P_{0}$ back to that of control. The patch was held at $-60 \mathrm{mV}$. $B$, Summary data for the effect of introducing PKA $_{6-22}$ after ATP inhibits cation channels. In this group, ATP produces an $\sim 45 \%$ decrease in $P_{0}$, but with the addition of $\mathrm{PKA}_{6-22}$, there is an $\sim 150 \%$ increase in $\mathrm{P}_{0}$ as activity returns to control levels $(n=9$ patches; $p<0.02$; paired Student's $t$ test).

would prevent reversal. The first PP blocker tested in this manner was okadaic acid, an inhibitor that is believed to be relatively more specific for PP2 than PP1 (Bialojan and Takai, 1988). Patches were excised into artificial intracellular saline containing $100 \mathrm{~nm}$ okadaic acid, which was followed by ATP, and finally $\mathrm{PKA}_{6-22}$. Surprisingly, in the presence of okadaic acid, $\mathrm{PKA}_{6-22}$ was still capable of initiating recovery in cation channel activity after a decreased $\mathrm{P}_{\mathrm{O}}$ ATP response $(n=4$ patches) (Fig. $6 A$ ). On average, ATP lowered $\mathrm{P}_{\mathrm{O}}$ by $\sim 50 \%$, which was reversed markedly by $\mathrm{PKA}_{6-22}$ with an almost $250 \%$ enhancement (Fig. $6 \mathrm{~B}$ ).

The inability of okadaic acid to prevent $\mathrm{PKA}_{6-22}$-induced reversal of the decreased $\mathrm{P}_{\mathrm{O}}$ ATP response could be attributable to its ineffectiveness as a PP inhibitor in bag cell neurons, and/or the PP responsible may be more similar to PP1 than PP2. Thus, microcystin-LR, an inhibitor with more equal specificity between PP1 and PP2 (MacKintosh et al., 1990), was used next. With $200 \mathrm{~nm}$ microcystin-LR bathing the cytoplasmic face of cation channels, the reduction in activity elicited by ATP was not reversed with application of $\mathrm{PKA}_{6-22}$ ( $n=5$ patches) (Fig. $6 C$ ). The mean decrease in $\mathrm{P}_{\mathrm{O}}$ brought about by ATP was just over $50 \%$, and instead of showing recovery, the $\mathrm{P}_{\mathrm{O}}$ actually went down slightly by $\sim 35 \%$ after $\mathrm{PKA}_{6-22}$ (Fig. 6D).

PKA inhibition did not alter the increased $P_{O}$ ATP response

Previous work on the cation channel demonstrated that the application of ATP to the cytoplasmic face could, in some cases, increased $\mathrm{P}_{\mathrm{O}}$ through the actions of closely associated PKC (Wilson et al., 1998; Magoski et al., 2002). If PKA were associated with the cation channel at the same time as $\mathrm{PKC}$, there may, in fact, be a competition between the two kinases for modulation of the activity of the channel in the presence of ATP. This would also have implications for how the regulatory complex may be organized during different states of excitability. To examine the possibility that PKA and PKC are simultaneously closely associated with certain cation channels, $\mathrm{PKA}_{6-22}$ was added to the cytoplasmic face of channels displaying an increased $\mathrm{P}_{\mathrm{O}}$ ATP response. If PKA was associated with the channel at the same time as PKC, inhibition of PKA should result in an even greater increase in $\mathrm{P}_{\mathrm{O}}$; however, cation channel activity did not rise further after the introduction of $\mathrm{PKA}_{6-22}$ (Fig. 7A). The increased $\mathrm{P}_{\mathrm{O}}$ ATP response amounted to an $\sim 250 \%$ increase in activity, which was followed by a small, $\sim 20 \%$ decrease, with PKA $_{6-22}(n=12$ patches) (Fig. $7 B)$.

\section{Discussion}

The inward current that depolarizes the bag cell neurons during the afterdischarge arises from a nonselective, $\mathrm{Ca}^{2+}$-permeable, voltage-dependent, noninactivating cationconductance (Kaczmarek and Strumwasser, 1984; Wilson and Kaczmarek, 1993; Wilson et al., 1996). Currents with similar properties have been shown to maintain prolonged, repetitive, and/or burst firing in a large number of functionally diverse neurons from multiple species (Wilson and Wachtel, 1974; Partridge et al., 1979; Green and Gillette, 1983; Stafstrom et al., 1985; Swandulla and Lux, 1985; Alonso and Llinas, 1989; Rekling and Feldman, 1997; Beurrier et al., 1999; Morisset and Nagy, 1999; Raman et al., 2000; Egorov et al., 2002; Perrier and Hounsgaard, 2002). Cation channel activation can also initiate activity-dependent changes to intrinsic excitability (Egorov 
et al., 2002; Zhang and Linden, 2003), which for the bag cell neurons leads to clear longterm changes in neuronal activity and animal behavior (Kupfermann, 1967; Kupfermann and Kandel, 1970; Pinsker and Dudek, 1977; Wilson and Kaczmarek, 1993; Wilson et al., 1996; Magoski et al., 2000, 2002). The upregulation of this channel during the afterdischarge is attributable to the sustained input of several second messengers and kinases (Conn and Kaczmarek, 1989; Magoski and Kaczmarek, 2003), including a persistent increase in PKC (Wayne et al., 1999). A close, physical association between PKC and the cation channel facilitates the afterdischarge by guaranteeing a precise timing and localization of increased enzyme activity leading to increased $\mathrm{P}_{\mathrm{O}}$.

In excised, inside-out patches, the closely associated PKC manifests itself as an increased $\mathrm{P}_{\mathrm{O}}$ after application of ATP to the cytoplasmic face. However, as shown in the present study, $\mathrm{P}_{\mathrm{O}}$ can also be decreased by ATP in a rapid and sustained manner. This suggests that the decreased $\mathrm{P}_{\mathrm{O}}$ ATP response is also attributable to a closely associated kinase activity phosphorylating the channel or a nearby protein. Alterations to channel phenotype, such as a change in $\mathrm{P}_{\mathrm{O}}$ with phosphorylation, are correlated with often unique changes in either the duration or number of exponentials required to fit the dwell times representing the kinetic profile of the channel (Colquhoun and Sigworth, 1995). Although the decreased $\mathrm{P}_{\mathrm{O}}$ ATP response is not associated with a change in the number of exponentials required to fit either the open- or closed-state dwell times, it is accompanied by a consistent $\sim 40 \%$ elevation to the third closed-state time constant, $t_{\mathrm{C} 3}$. An increase in $t_{\mathrm{C} 3}$ suggests that the channel favors remaining closed, resulting in the reduced activity characteristic of the decreased $\mathrm{P}_{\mathrm{O}}$ ATP response. Wilson and Kaczmarek (1993) showed that, in the presence of ATP, application of the catalytic subunit of bovine PKA to the cytoplasmic face caused a $40 \%$ decrease in $\mathrm{P}_{\mathrm{O}}$ and a similar increase in $t_{\mathrm{C} 3}$ duration. The degree of similarity between the decreased $\mathrm{P}_{\mathrm{O}}$ ATP response and the effects of exogenous PKA raises the possibility that the ATP-induced drop in activity is mediated by a closely associated PKA-like activity.

A cation channel-PKA association is further reinforced by the ability of $\mathrm{PKA}_{6-22}$ to prevent the decreased $\mathrm{P}_{\mathrm{O}}$ ATP response. $\mathrm{PKA}_{6-22}$ is a very specific blocker of PKA, based on the endogenous PKA inhibitor protein (PKI) (Walsh et al., 1971; Ashby and Walsh, 1972; Glass et al., 1989). PKI was shown by Adams and Levitan (1982) to be extremely effective at inhibiting Aplysia brain PKA in a biochemical assay. Furthermore, PKI and/or its derived peptides, $\mathrm{PKA}_{6-22}$ and $\mathrm{PKA}_{5-24}$, have been used to demonstrate a role for PKA in the control of excitability and action potential height in the bag cell neurons themselves (Conn et al., 1989), as well as phenomena in other marine preparations, in-
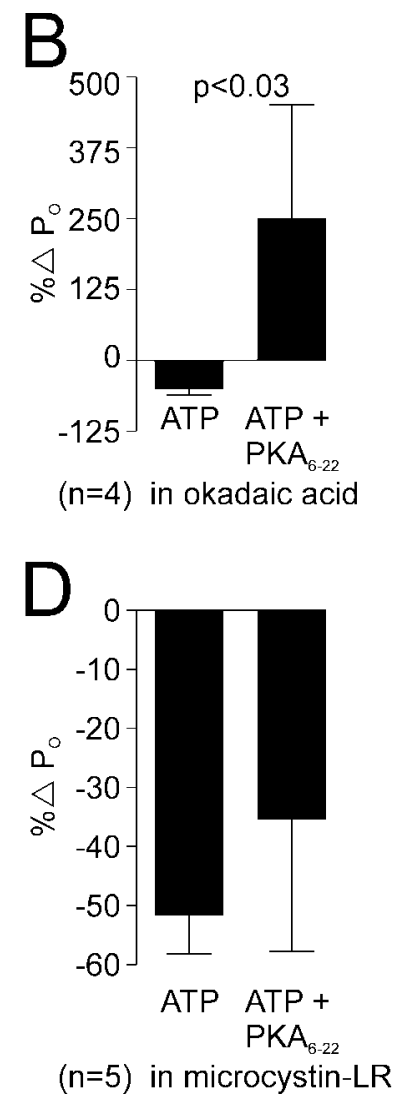

$(n=5)$ in microcystin-LR

Figure 6. Reversal of the decreased $P_{0}$ ATP response by $P A_{6-22}$ is prevented by microcystin-LR but not okadaic acid. $A$, Pretreatment with okadaic acid does not alter the ability of PKA $_{6-22}$ to reverse the decreased $P_{0}$ ATP response. Top trace, $A$ ffect of okadaic acid on PKA okadaic acid decreases $P_{0}$ by $\sim 50 \%$, and after introduction of $P_{K A}$, channel activity returns to pre-ATP levels with a near increase in $\mathrm{P}_{0}$ ( $n=4$ patches; $p<0.03$; Wilcoxon matched-pairs test). $C$, Pretreatment with microcystin-LR prevents cytoplasmicface bathed by 200 nm microcystin-LR. Middle trace, Delivery of 1 mu ATP results in a $P_{0}$ decrease Bottom trace, When response. While in the presence of microcystin- $L R$, the addition of ATP causes a slightly $>50 \%$ decrease in $P_{0}$. This drop in activity is not reversed with the subsequent application of $\mathrm{PKA}_{6-22}$, and, in fact, the $\mathrm{P}_{0}$ drops even further by $\sim 35 \%$ ( $n=5$ patches).

cluding Aplysia sensory neuron spike broadening (Castellucci et al., 1982), serotonin-induced increase of $\mathrm{K}^{+}$current in Aplysia neuron R15 (Adams and Levitan, 1982), and transmitter release from the squid giant synapse (Hilfiker et al., 2001). Finally, in excised, inside-out patch-clamp recordings from several preparations, these peptides have established that PKA, through a close, physical association, can regulate $\mathrm{Ca}^{2+}$-activated $\mathrm{K}^{+}$channels (Bielefeldt and Jackson, 1994; Esguerra et al., 1994; Wang and Kotlikoff, 1996).

When a kinase is found to be closely associated with a channel, a phosphatase is often present to act as a balance (Bielefeldt and Jackson, 1994; Reinhart and Levitan, 1995; Wilson et al., 1998; Davare et al., 2001; Magoski et al., 2002; Marx et al., 2002), and the PKA-mediated decrease of cation channel $\mathrm{P}_{\mathrm{O}}$ is no exception. When $\mathrm{PKA}_{6-22}$ is applied after the ATP-induced decrease in $\mathrm{P}_{\mathrm{O}}$ occurs, activity recovers toward control levels. In addition, pretreating patches with microcystin-LR, a PP inhibitor, prevents $\mathrm{PKA}_{6-22}$ from reversing the response. These data suggest that a $\mathrm{PP}$ is closely associated with the channel, and when PKA is inhib- 


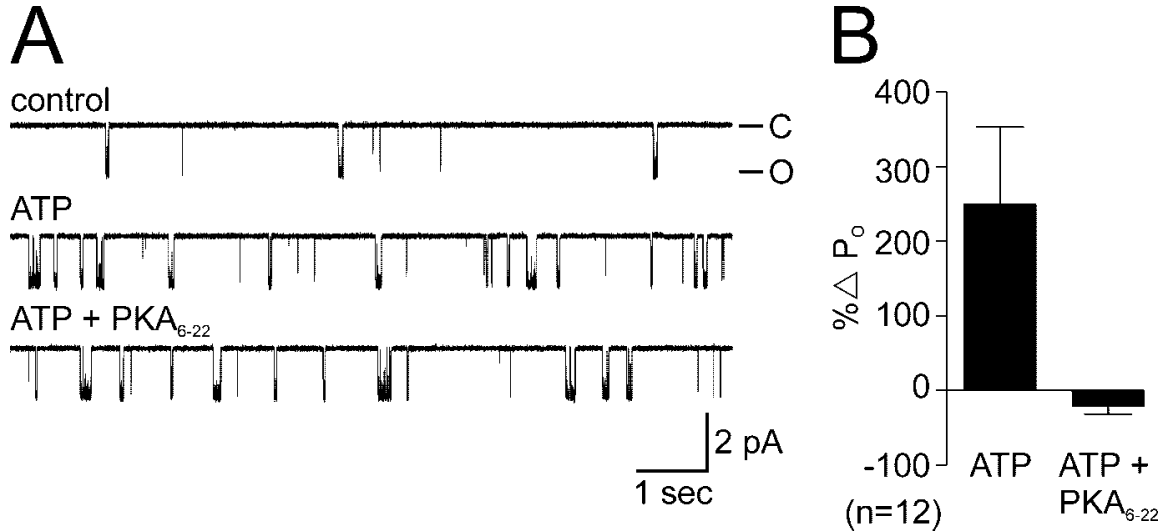

Figure 7. The increased $\mathrm{P}_{0}$ ATP response is not augmented by $\mathrm{PKA}_{6-22}$. A, $\mathrm{PKA}_{6-22}$ does not alter the magnitude of the increased $P_{0}$ ATP response. Top trace, An excised, inside-out patch recording of a cation channel. Middle trace, Application of $1 \mathrm{~mm}$ ATP to the cytoplasmic face produces a robust $P_{0}$ increase. Bottom trace, The $P_{0}$ remains unchanged after the addition of $1 \mu \mathrm{m}$ $\mathrm{PKA}_{6-22}$. The patch was held at $-60 \mathrm{mV}$. B, Summary data for the lack of an effect of PKA ${ }_{6-22}$ on the increased $P_{0}$ ATP response. This set of responsive channels shows an $\sim 250 \%$ elevation in $\mathrm{P}_{0}$ with the addition of ATP. The enhancement is not altered further when $\mathrm{PKA}_{6-22}$ is added, because the $\mathrm{P}_{0}$ shows only an $\sim 20 \%$ drop that is not significantly different from zero ( $n=12$ patches; $p>0.05$; one-sample $t$ test).

ited, the phosphatase is free to dephosphorylate the substrate. The effectiveness of microcystin-LR is in contrast to another PP inhibitor, okadaic acid, which failed to prevent reversal of the response by $\mathrm{PKA}_{6-22}$. Okadaic acid has a greater specificity for PP2 over PP1 (Bialojan and Takai, 1988), whereas microcystin-LR has a similar specificity between PP1 and PP2 (MacKintosh et al., 1990). In Aplysia, the major neuronal plasma membrane-bound phosphatase is PP1-like (Endo et al., 1995), and both the PP1and PP2-like enzymes share a similar sensitivity to microcystinLR (Ichinose et al., 1990). Moreover, microcystin-LR attenuates the FMRFamide-induced $\mathrm{K}^{+}$current (Endo et al., 1995) and prolongs serotonin-induced spike broadening (Ichinose et al., 1990) in pleural sensory neurons, as well as prevents the reversal of PKC-dependent phosphorylation of the bag cell neuron cation channel (Wilson et al., 1998). Thus, it is probable that a PP1-like

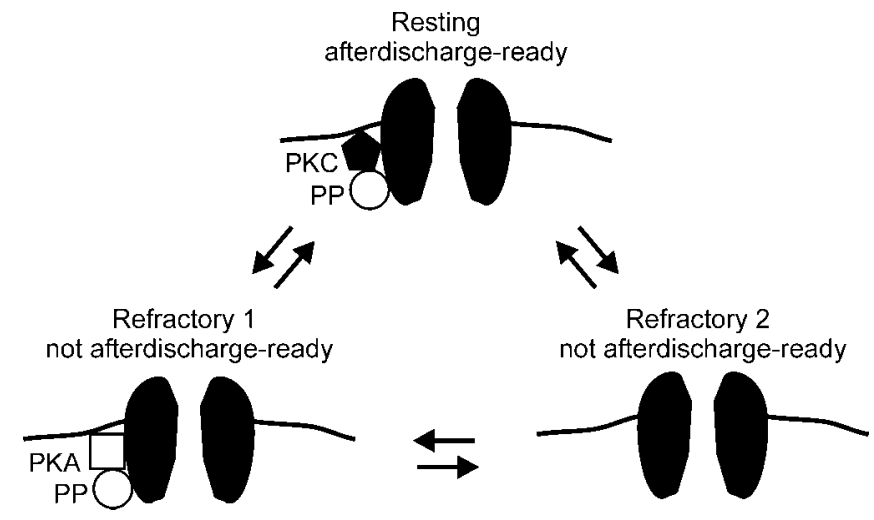

Figure 8. Model for altering the constituents of the cation channel regulatory complex under different states of excitability. Top, At rest, when the bag cell neurons are ready to afterdischarge, the regulatory complex consists of a closely associated, stimulatory PKC along with a counterbalancing PP. This would represent channels that display the increased $\mathrm{P}_{0}$ ATP response. Bottom left, After an afterdischarge, the bag cell neurons become refractory and, despite additional stimulation, are unable to afterdischarge further. This first refractory scenario has an inhibitory PKA, as well as a counterbalancing PP, associated with the cation channel. The downregulation of cation channel activity by PKA may contribute to the inexcitability seen during refractoriness. Bottom right, $A$ second refractory scenario has a cation channel that lacks a regulatory complex altogether. Arrows indicate the possibility of transition between different states of the complex by altering the component enzymes. phosphatase dephosphorylates the cation channel after the actions of PKA or PKC.

The decrease or increase in $\mathrm{P}_{\mathrm{O}}$ observed after ATP seems to depend on whether PKA or PKC is closely associated with the channel. Given that introducing $\mathrm{PKA}_{6-22}$ after an increased $\mathrm{P}_{\mathrm{O}}$ ATP response does not result in additional elevation of cation channel activity suggests the association of PKC precludes association of PKA. In addition to describing that $\sim 30 \%$ of channels/animals displayed a decreased $\mathrm{P}_{\mathrm{O}}$ with ATP, Magoski (2003), as well as Magoski and Kaczmarek (unpublished observations), also reported that $\sim 40 \%$ of cation channels excised from refractory bag cell neurons displayed a decreased $\mathrm{P}_{\mathrm{O}}$ ATP response, compared with none of the channels from resting neurons. The bag cell neurons become refractory after termination of the afterdischarge and remain in a state in which bursting cannot be initiated for $\sim 18 \mathrm{hr}$ (Conn and Kaczmarek, 1989). Whereas $\mathrm{Ca}^{2+}$ entry is key to initiating refractoriness (Kaczmarek and Kauer, 1983; Magoski et al., 2000), a clear, mechanistic understanding of the refractory period is incomplete (Zhang et al., 2002). However, it has been established that electrical or pharmacological stimulation of refractory neurons does not elicit the cumulative depolarization that drives the afterdischarge (Kaczmarek and Kauer, 1983; Kauer and Kaczmarek, 1985; Wilson et al., 1996). Because the cation channel underlies this depolarization, its regulation may be altered under such circumstances. Indeed, based on their finding that exogenous PKA lowers channel activity, Wilson and Kaczmarek (1993) concluded that refractoriness may involve PKA-dependent inhibition of the cation channel. If this is the case, then the cation channel-PKA association documented here provides a means to promote or maintain refractoriness. In addition, the constituents of the cation channel regulatory complex could be altered to further different states of excitability. Before and throughout the afterdischarge, PKC is associated with the channel, whereas during the transition to the refractory period, PKC dissociates and PKA potentially associates with the channel (Fig. 8, schematic).

Several mechanisms may contribute to organizing the cation channel regulatory complex. For example, both the PP and either PKC or PKA could bind directly to the channel. Transition between different regulators would then be achieved by PKA displacing PKC and vice versa. Alternatively, the association or upregulation of one kinase could simply sterically hinder the actions of another, permanently associated kinase. As suggested by Magoski et al. (2002), the cation channel and its regulatory enzymes could also be brought together by a scaffolding protein. Exchange of PKA for PKC could be regulated by altering the affinity of the scaffold for one kinase over the other, perhaps with steric hindrance preventing dual kinase occupation. Once in close proximity, presumably PKA or PKC regulates the channel by phosphorylating it on distinct sites, both of which could be dephosphorylated by the PP. In contrast, a secondary channel-associated protein could be the actual target of phosphorylation, and in turn this protein alters channel gating phenotype.

Complexes of kinases and/or phosphatases with ion channels 
have been documented for a large number of voltage-gated and ionotropic channels from various species (Chung et al., 1991; Bielefeldt and Jackson, 1994; Rosenmund et al., 1994; Reinhart and Levitan, 1995; Holmes et al., 1996; Yu et al., 1997; Tibbs et al., 1998; Brandon et al., 1999; Tsunoda and Zucker, 1999; Davare et al., 2001; Huang et al., 2001; Marx et al., 2002; Nitabach et al., 2002; Zhou et al., 2002; Gingrich et al., 2004). For the bag cell neurons, the cation channel can be considered an integration point at which appropriate signaling molecules converge in a complex to control excitability. The association of different regulators at different times (e.g., PKA/PP vs PKC/PP) suggests that a general mechanism for diversifying modulation can be found in rearranging the constituents of a given channel complex. This strategy of "regulating the regulators" is well suited for precisely modulating ion channel function and excitability, particularly over long time periods.

\section{References}

Adams WB, Levitan IB (1982) Intracellular injection of protein kinase inhibitor blocks the serotonin-induced increase in $\mathrm{K}^{+}$conductance in Aplysia neuron R15. Proc Natl Acad Sci USA 79:3877-3880.

Alonso A, Llinas RR (1989) Subthreshold $\mathrm{Na}^{+}$-dependent theta-like rhythmicity in stellate cells of entorhinal cortex layer II. Nature 342:175-177.

Ashby CD, Walsh DA (1972) Characterization of the interaction of a protein inhibitor with adenosine $3^{\prime}, 5^{\prime}$-monophosphate-dependent protein kinases. J Biol Chem 247:6637-6642.

Beurrier C, Congar P, Bioulac B, Hammond C (1999) Subthalamic nucleus neurons switch from single-spike activity to burst firing mode. J Neurosci 19:599-609.

Bialojan C, Takai A (1988) Inhibitory effect of a marine-sponge toxin, okadaic acid, on protein phosphatases. Specificity and kinetics. Biochem J 256:283-290.

Bielefeldt K, Jackson MB (1994) Phosphorylation and dephosphorylation modulate a $\mathrm{Ca}^{2+}$-activated $\mathrm{K}^{+}$channel in rat peptidergic nerve terminals. J Physiol (Lond) 475:241-254.

Brandon NJ, Uren JM, Kittler JT, Wang H, Olsen R, Parker PJ, Moss SJ (1999) Subunit-specific association of protein kinase $\mathrm{C}$ and the receptor for activated C kinase with GABA type A receptors. J Neurosci 19:9228-9234.

Castellucci VF, Nairn A, Greengard P, Schwartz JH, Kandel ER (1982) Inhibitor of adenosine $3^{\prime}, 5^{\prime}$-monophosphate-dependent protein kinase blocks presynaptic facilitation in Aplysia. J Neurosci 2:1673-1681.

Chung S, Reinhart PH, Martin BL, Brautigan D, Levitan IB (1991) Protein kinase activity closely associated with a reconstituted calcium-activated potassium channel. Science 253:560-562.

Colquhoun D, Sigworth FJ (1995) Fitting and statistical analysis of singlechannel records. In: Single channel recording, Ed 2 (Sakmann B, Neher E, eds), pp 483-587. New York: Plenum.

Conn PJ, Kaczmarek LK (1989) The bag cell neurons of Aplysia. Mol Neurobiol 3:237-273.

Conn PJ, Strong JA, Azhderian EM, Nairn AC, Greengard P, Kaczmarek LK (1989) Protein kinase inhibitors selectively block phorbol ester- or forskolin-induced changes in excitability of Aplysia neurons. J Neurosci 9:473-479.

Davare MA, Avdonin V, Hall DD, Peden EM, Burette A, Weinberg RJ, Horne MC, Hoshi T, Hell JW (2001) A fl 2 adrenergic receptor signalling complex assembled with the $\mathrm{Ca}^{2+}$ channel $\mathrm{Ca}_{\mathrm{V}}$ 1.2. Science 293:98-101.

Egorov AV, Hamam BN, Fransen E, Hasselmo ME, Alonso AA (2002) Graded persistent activity in entorhinal cortex neurons. Nature 420:173-178.

Endo S, Critz SD, Byrne JH, Shenolikar S (1995) Protein phosphatase-1 regulates outward $\mathrm{K}^{+}$currents in sensory neurons of Aplysia californica. J Neurochem 64:1833-1840.

Esguerra M, Wang J, Foster CD, Adelman JP, North RA, Levitan IB (1994) Cloned $\mathrm{Ca}^{2+}$-dependent $\mathrm{K}^{+}$channel modulation by a functionally associated protein kinase. Nature 369:563-565.

Gingrich JR, Pelkey KA, Fam SR, Huang Y, Petralia RS, Wenthold RJ, Salter MW (2004) Unique domain anchoring of Src to synaptic NMDA receptors via the mitochondrial protein NADH dehydrogenase subunit 2. Proc Natl Acad Sci USA 101:6237-6242.
Glass DB, Lundquist LJ, Katz BM, Walsh DA (1989) Protein kinase inhibitor-(6-22)-amide peptide analogs with standard and nonstandard amino acid substitutions for phenylalanine 10. J Biol Chem 264:14579-14584

Green DJ, Gillette R (1983) Patch- and voltage-clamp analysis of cyclic AMP-stimulated inward current underlying neurone bursting. Nature 306:784-785.

Hilfiker S, Czernik AJ, Greengard P, Augustine GJ (2001) Tonically active protein kinase A regulates neurotransmitter release at the squid giant synapse. J Physiol (Lond) 531:141-146.

Hille B (2001) Ionic channels of excitable membranes, Ed 3. Sunderland, MA: Sinauer Associates.

Holmes TC, Fadool DA, Ren R, Levitan IB (1996) Association of Src tyrosine kinase with a human potassium channel mediated by $\mathrm{SH} 3$ domain. Nature 274:2089-2091.

Huang Y-Q, Lu W-Y, Ali DW, Pelkey KA, Pitcher GM, Lu YM, Aoto H, Roder JC, Sasaki T, Salter MW, MacDonald JF (2001) CAK/Pyk2 kinase is a signalling link for induction of long-term potentiation in CA1 hippocampus. Neuron 29:485-496.

Ichinose M, Endo S, Critz SD, Shenolikar S, Byrne JH (1990) MicrocystinLR, a potent protein phosphatase inhibitor, prolongs the serotonin- and cAMP-induced currents in sensory neurons of Aplysia californica. Brain Res 533:137-140.

Kaczmarek LK, Kauer JA (1983) Calcium entry causes a prolonged refractory period in peptidergic neurons of Aplysia. J Neurosci 3:2230-2239.

Kaczmarek LK, Strumwasser F (1984) A voltage-clamp analysis of currents underlying cyclic AMP-induced membrane modulation in isolated peptidergic neurons of Aplysia. J Neurophysiol 52:340-349.

Kauer JA, Kaczmarek LK (1985) Peptidergic neurons of Aplysia lose their response to cyclic adenosine $3^{\prime}, 5^{\prime}$-monophosphate during a prolonged refractory period. J Neurosci 5:1339-1345.

Kupfermann I (1967) Stimulation of egg laying: possible neuroendocrine function of bag cells of abdominal ganglion of Aplysia californica. Nature 216:814-815

Kupfermann I, Kandel ER (1970) Electrophysiological properties and functional interconnections of two symmetrical neurosecretory clusters (bag cells) in abdominal ganglion of Aplysia. J Neurophysiol 33:865-876.

Levitan IB, Kaczmarek LK (2002) The neuron: cell and molecular biology, Ed 3. New York: Oxford UP.

MacKintosh C, Beattie KA, Klumpp S, Cohen P, Codd GA (1990) Cyanobacterial microcystin-LR is a potent and specific inhibitor of protein phosphatases 1 and 2A from both mammals and higher plants. FEBS Lett 264:187-192.

Magoski NS (2003) Neuronal excitability and tyrosine kinases regulate PKC-dependent modulation of a non-selective cation channel in Aplysia bag cell neurons. Soc Neurosci Abstr 29:168.6.

Magoski NS, Kaczmarek LK (2003) Protein kinases and neuronal excitability. In: Encyclopedia of neuroscience, Ed 3 (Adelman G, Smith BH, eds), CD-ROM. New York: Elsevier.

Magoski NS, Knox RJ, Kaczmarek LK (2000) Activation of a $\mathrm{Ca}^{2+}$ permeable cation channel produces a prolonged attenuation of intracellular $\mathrm{Ca}^{2+}$ release in Aplysia bag cell neurones. J Physiol (Lond) 522 2:271-283.

Magoski NS, Wilson GF, Kaczmarek LK (2002) Protein kinase modulation of a neuronal cation channel requires protein-protein interactions mediated by an Src homology 3 domain. J Neurosci 22:1-9.

Marx SO, Kurokawa J, Reiken S, Motoike H, D'Armiento J, Marks AR, Kass RS (2002) Requirement of a macromolecular signalling complex for adrenergic receptor modulation of the KCNQ1-KCNE1 potassium channel. Science 295:496-499.

Morisset V, Nagy F (1999) Ionic basis for plateau potentials in deep dorsal horn neurons of the rat spinal cord. J Neurosci 19:7309-7316.

Nitabach MN, Llamas DA, Thompson IJ, Collins KA, Holmes TC (2002) Phosphorylation-dependent and phosphorylation-independent modes of modulation of Shaker family voltage-gated potassium channels by Src family protein tyrosine kinases. J Neurosci 22:7913-7922.

Partridge LD, Thompson SH, Smith SJ, Connor JA (1979) Current-voltage relationships of repetitively firing neurons. Brain Res 164:69-79.

Perrier J-F, Hounsgaard J (2002) $\mathrm{Ca}^{2+}$-activated non-selective cationic current (ICAN) in turtle motoneurons. J Neurophysiol 82:730-735.

Pinsker HM, Dudek FE (1977) Bag cell control of egg laying in freely behaving Aplysia. Science 197:490-493. 
Raman IM, Gustafuson AE, Padgett D (2000) Ionic currents and spontaneous firing in neurons isolated from the cerebellar nuclei. J Neurosci 20:9004-9016.

Reinhart PH, Levitan IB (1995) Kinase and phosphatase activities intimately associated with a reconstituted calcium-dependent potassium channel. J Neurosci 15:4572-4579.

Rekling JC, Feldman JL (1997) Calcium-dependent plateau potentials in rostral ambiguus neurons in the newborn mouse brain stem in vitro. J Neurophysiol 78:2483-2492.

Rosenmund C, Carr DW, Bergeson SE, Nilaver G, Scott JD, Westbrook GL (1994) Anchoring of protein kinase $\mathrm{A}$ is required for modulation of AMPA/kainate receptors on hippocampal neurons. Nature 368:853-856.

Rothman BS, Weir G, Dudek FE (1983) Egg-laying hormone: direct action on the ovotestis of Aplysia. Gen Comp Endocrinol 52:134-141.

Stafstrom CE, Schwindt PC, Chubb MC, Crill WE (1985) Properties of persistent sodium conductance and calcium conductance of layer $\mathrm{V}$ neurons from cat sensorimotor cortex in vitro. J Neurophysiol 53:153-170.

Swandulla D, Lux HD (1985) Activation of a nonspecific cation conductance by intracellular $\mathrm{Ca}^{2+}$ elevation in bursting pacemaker neurons of Helix pomatia. J Neurophysiol 54:1430-1443.

Tibbs VC, Gray PC, Catterall WA, Murphy BJ (1998) AKAP15 anchors cAMP-dependent protein kinase to brain sodium channels. J Biol Chem 273:25783-25788.

Tsunoda S, Zuker CS (1999) The organization of INAD-signalling complexes by a multivalent PDZ domain protein in Drosophila photoreceptor cells ensures sensitivity and speed of signalling. Cell Calcium 26:165-171.

Walsh DA, Ashby CD, Gonzalez C, Calkins D, Fischer EH, Krebs EG (1971) Purification and characterization of a protein inhibitor of adenosine 3',5'-monophosphate-dependent protein kinases. J Biol Chem 246:1977-1985.
Wang Z-W, Kotlikoff MI (1996) Activation of $\mathrm{K}_{\mathrm{Ca}}$ channels in airway smooth muscle cells by endogenous protein kinase A. Am J Physiol 271:L100-L105.

Wayne NL, Lee W, Kim YJ (1999) Persistent activation of calcium-activated and calcium-independent protein kinase $\mathrm{C}$ in response to electrical afterdischarge from peptidergic neurons of Aplysia. Brain Res 834:211-213.

Wilson GF, Kaczmarek LK (1993) Mode-switching of a voltage-gated cation channel is mediated by a protein kinase A-regulated tyrosine phosphatase. Nature 366:433-438.

Wilson GF, Richardson FC, Fisher TE, Olivera BM, Kaczmarek LK (1996) Identification and characterization of $\mathrm{a} \mathrm{Ca}^{2+}$-sensitive nonspecific cation channel underlying prolonged repetitive firing in Aplysia neurons. J Neurosci 16:3661-3671.

Wilson GF, Magoski NS, Kaczmarek LK (1998) Modulation of a calciumsensitive nonspecific cation channel by ATP via a closely-associated protein kinase. Proc Natl Acad Sci USA 95:10938-10943.

Wilson WA, Wachtel H (1974) Negative resistance characteristic essential for the maintenance of slow oscillations in bursting neurons. Science 186:932-934.

Yu X-M, Askalan R, Keil GJ, Salter MW (1997) NMDA channel regulation by channel-associated protein tyrosine kinase src. Science 275:674-678.

Zhang W, Linden DJ (2003) The other side of the engram: experience-driven changes in neuronal intrinsic excitability. Nat Neurosci Rev 4:885-900.

Zhang Y, Magoski NS, Kaczmarek LK (2002) Prolonged activation of $\mathrm{Ca}^{2+}$. activated $\mathrm{K}^{+}$current contributes to the long-lasting refractory period of Aplysia bag cell neurons. J Neurosci 22:10134-10141.

Zhou Y, Wang J, Wen H, Kucherovsky O, Levitan IB (2002) Modulation of Drosophila slowpoke calcium-dependent potassium channel activity by bound protein kinase A catalytic subunit. J Neurosci 22:3855-3863. 